\title{
Procrastination and problematic new media use: the mediating role of future anxiety
}

\author{
Aneta Przepiorka $^{1}$ (D) $\cdot$ Agata Blachnio $^{1} \cdot$ Andrzej Cudo $^{1}$
}

Accepted: 20 April 2021 / Published online: 21 May 2021

(C) The Author(s) 2021

\begin{abstract}
In recent years, the new media have become so attractive that they are used for meetings, entertainment, and work. People more and more often use Facebook or phones instead of doing their work or family duties. The main aim of the present study was to test the mediating role of future anxiety in the relationship between procrastination and problematic new media use. The participants were students $(N=478)$, aged 18 to $27(M=19.93, S D=1.77) ; 64 \%$ of the sample were women. The General Procrastination Scale, the Decisional Procrastination Scale, the Facebook Intrusion Questionnaire, the Adapted Mobile Phone Use Habits, and the Future Anxiety Scale-Short Form were used. The study showed that those students who procrastinated often reported a high tendency to engage in problematic new media use and a high level of future anxiety. The findings of the study have important implications for research on problematic Facebook and mobile phone use. They may be applicable in the work of psychologists, psychiatrists, and therapists, both in prevention and in developing online addiction therapies.
\end{abstract}

Keywords Facebook intrusion $\cdot$ Problematic mobile phone use $\cdot$ Procrastination $\cdot$ Future anxiety

\section{Introduction}

Although procrastination is not a new phenomenon (Steel, 2010), new possibilities of procrastinating have appeared with the emergence of modern forms of technology (Odaci, 2011; Przepiorka et al., 2016; Reinecke, Meier, Aufenanger, et al., 2018a). Despite the experience of negative consequences, some people log on to Facebook too often or continually reach for their mobile phones. Why do some people begin to use new media in problematic ways when they procrastinate and escape from doing their tasks and duties or from making decisions? New media are digital media that enable interaction, link people in two-way communication, and involve a certain form of information technology (Logan, 2010). The contents provided by new media are easily processed and stored; they can be easily found and accessed. According to the Cambridge Business English Dictionary (2019), the term "new media" refers to products or services that provide information or entertainment by means of phones or the Internet rather than traditional methods such as television or

Aneta Przepiorka

aneta.przepiorka@gmail.com; aneta.przepiorka@kul.pl

1 Institute of Psychology, The John Paul II Catholic University of Lublin, Al. Racławickie 14, 20-950 Lublin, Poland newspapers. Sites such as Facebook can be regarded as a type of new media (Giles, 2010). The use of social networking sites increases every year (Saiphoo et al., 2020). Excessive media use may be a result of postponing the performance of certain tasks and escaping from duties into the virtual world (Meier et al., 2016; Reinecke, Meier, Beutel, et al., 2018b). Using Facebook or mobile phone instead of working on a task is becoming increasingly frequent (e.g., David et al., 2015). New terms appear in the literature that refer to using the Internet for private purposes unrelated to the task one is working on, such as online procrastination (Goroshit \& Hen, 2018) or cyberloafing (Akbulut et al., 2017). The link between the use of modern technology and escape behaviors may therefore be a promising direction for research.

In this article we intend to investigate the relationship of procrastination to Facebook intrusion (Elphinston \& Noller, 2011) and problematic mobile phone use (Smetaniuk, 2014), jointly referred to as problematic new media use. The studies reported in the literature so far show the robust predictive power of future time perspective for Internet and Facebook addictions (Chittaro \& Vianello, 2013; Przepiorka et al., 2019; Przepiorka \& Blachnio, 2016). To broaden these results, it is worth investigating one of the aspects of future time perspective, future anxiety (FA; Zaleski, 1991), whose relation to problematic new media use has rarely been a subject of research. 


\section{Procrastination and Problematic New Media Use}

Procrastination is a tendency to postpone a previous intention to begin or complete an important activity despite the negative effect of this postponement on the individual (Lay, 1986). Procrastinators experience the negative consequences of their behavior in various domains: health, social, occupational, and mental (Karatas, 2015; Kim \& Seo, 2015; Hen \& Goroshit, 2020; Sirois, 2014a, 2014b; Lay, 1986; Eckert et al., 2016). They are more prone to diseases (Sirois \& Pychyl, 2013) and their mental condition is weaker (Stead et al., 2010); they have lower academic and work achievement (Nguyen et al., 2013; Sirois et al., 2003). Procrastination can be treated as a form of failure in self-regulation or self-control (Steel, 2007). It usually takes place in the case of activities regarded as unpleasant, tiresome, or challenging and associated with a reward delayed in time (Sirois \& Pychyl, 2013). Authors distinguish behavioral (arousal and avoidant) and cognitive (decisional) procrastination (Ferrari, 2000). General procrastination refers generally to avoidant behavior, which manifests itself in the frequency of postponing or delaying the commencement or completion of everyday behavioral tasks or activities (Grund \& Fries, 2018; Fernie et al., 2017; Ferrari \& Roster, 2018). Decisional procrastination, in contrast, is a more specific type of procrastination (Goroshit \& Hen, 2018) and refers to the tendency to purposely delay making decisions within a specific time frame (Effert \& Ferrari, 1989; Mann, 1982). Previous studies revealed moderate intercorrelations between general and decisional procrastination (Harriott \& Ferrari, 1996) reported. In the light of the theory of action control (Kuhl, 1984), these two types of procrastination are regulated by other volitional control systems distinguished by Kuhl (Milgram \& Tenne, 2000). According to many authors, decisional procrastination and general procrastination should be distinguished because they are associated with personality traits, chronotype, and time perspectives in different ways (e.g., Tibbett \& Ferrari, 2015). The tendency to postpone making decisions was more strongly related to neuroticism, while avoidant procrastination was more strongly related to conscientiousness (Milgram \& Tenne, 2000). Similarly, some researchers consider general procrastination as a kind of personality disposition associated with self-efficacy and selfregulation (Gropel \& Steel, 2008); others mention also certain situational determinants, such as stress or the characteristics of the task to be performed (Díaz-Morales \& Ferrari, 2015). Decisional procrastination, by contrast, is often perceived as cognitive failure (Ferrari, 2000), involving a delay in accessing information about the alternatives available or certain memory deficits in processing complex information.

Facebook intrusion refers to the lack of control over one's Facebook use, which leads to excessive Facebook involvement (Elphinston \& Noller, 2011). There are three stages of Facebook intrusion: (1) withdrawal, (2) relapse and reinstatement, and (3) euphoria. People who feel a strong bond with Facebook are unable to stop using it and cannot control this. They have a sense of losing contact with others when they cannot use Facebook and experience rapture when they can access it again (Elphinston \& Noller, 2011). Facebook intrusion may be one of the manifestations of Facebook addiction (e.g., Błachnio \& Przepiorka, 2016). The other new media use variable, problematic mobile phone use, refers to difficulty in controlling the use of one's phone, which translates into negative consequences in everyday life (Davey \& Davey, 2014; De-Sola Gutiérrez et al., 2016). The following symptoms are usually listed: consciously using a mobile phone in situations in which this is dangerous or forbidden; problems with family and friends, accompanied by a loss of interest in other activities; health, mental, social, and work-related problems; problems in controlling mobile phone use and difficulties in ceasing to use the mobile; insomnia and sleep problems (De-Sola Gutiérrez et al., 2016; Lepp et al., 2016). Problematic mobile phone use has certain features in common with a whole spectrum of other behavioral addictions (Lepp et al., 2014).

Previous studies have shown that the tendency to procrastinate is related to Internet addiction (Geng et al., 2018; Kim et al., 2017), Facebook addiction (Przepiorka \& Blachnio, 2016), and excessive mobile phone use (Qaisar et al., 2017). A recent study has shown that using Facebook may be a way of procrastinating (Meier et al., 2016). The authors define procrastination with Facebook as a kind of behavioral dysfunction stemming from inadequate self-control. Habitual Facebook checking and high Facebook enjoyment have been identified as predictors of the frequency of procrastination with online media such as Facebook.

\section{Future Anxiety as a Mediator}

Previous studies have revealed a relationship between procrastination and time perspective, particularly future time perspective (Díaz-Morales \& Ferrari, 2015). It is for the future that we set goals, make plans, and do scheduled tasks (Nuttin, 1964). What is more, it can be said that postponing certain actions is projected into the future, and it is in the future that the consequences of this behavior will be experienced (Rebetez et al., 2016).

A meta-analysis revealed a negative relationship between procrastination and future time perspective (Sirois, 201). A study using the Zimbardo Time Perspective Inventory (ZTPI; Zimbardo \& Boyd, 1999) showed that there was a positive correlation between procrastination and presenthedonistic time orientation. Authors using a different measure, the Temporal Orientation Scale (Jones et al., 1996), found procrastination to be negatively related to future orientation, but not related at all to present time orientation (Specter \& Ferrari, 2000). Moreover, they reported associations of decisional procrastination with low future orientation and high past orientation. A different study, conducted by Jackson 
et al. (2003), in which negative affect was controlled for, showed that academic procrastination was positively related to negative evaluation of the past and a fatalistic view of the present and negatively related to future time perspective. In sum, a body of research on various kinds of procrastinationacademic, decisional, and general - has shown a negative relationship between procrastination and future time perspective (Díaz-Morales et al., 2008; Ferrari \& Díaz-Morales, 2007; Gupta et al., 2012; Jackson et al., 2003; Jones et al., 1996; Specter \& Ferrari, 2000).

Many authors highlight the need to approach future time perspective as a multidimensional construct (Cate \& John, 2007; Kooij et al., 2013), as otherwise the picture of perceived future is oversimplified (Carelli et al., 2011). In the literature, the main emphasis is placed on the positive dimension of the future, which is conducive to goal achievement and plays an important motivational role (Zimbardo \& Boyd, 1999). There are few studies, however, that investigate the negative aspect of the future, which also has a strong influence on well-being as well as on mental and physical condition (Holman \& Silver, 1998; van Beek et al., 2011). One of the concepts related to future time perspective is future anxiety (Zaleski, 1996), which refers to uncertainty, worry, and concern about what may happen in the future. It is cognitive rather than emotional. Future anxiety refers to how people react to fear, to personal experiences, and to current events (Zaleski, 1991).

Few studies have examined the potential link between procrastination and anxiety. They have, for instance, revealed a relationship between general anxiety and procrastination (Cambridge, 2019; Farran, 2004; Glick et al., 2014) and between anxiety and academic procrastination (Rahardjo et al., 2013). Students who scored higher on anxiety more often engaged in academic procrastination when using computers. Another study showed that high anxiety was associated with a higher level of procrastination in female students (Kamran \& Fatima, 2013).

Earlier studies have already shown a relationship between future time perspective and problematic Internet or Facebook use (Chittaro \& Vianello, 2013; Lukavska, 2012; Przepiorka $\&$ Blachnio, 2016). They revealed a negative relationship between future time perspective and Internet and Facebook addictions (Przepiorka \& Blachnio, 2016). Future time perspective, which is a positive future orientation associated with making plans and formulating goals, was a negative predictor of Internet addiction, Facebook intensity, and Facebook intrusion. Moreover, future time perspective with two dimensions (long future and long-term goals) had predictive power for Internet addiction in emerging adults (Przepiorka et al., 2019). Future time perspective acts as a buffer against two types of addiction: Facebook and Internet addictions (Przepiorka \& Blachnio, 2016). A recent study (Liu et al., 2018) showed that future time perspective partially mediated the relationship between mobile phone addiction and arousal and avoidant procrastination. The study investigated the positive dimension of future time perspective, comprising domains such as behavioral commitment, future efficacy, far goal orientation, future intention, and consciousness of purpose. Future time perspective was negatively related to procrastination (Gupta et al., 2012). The result showed that the mediating effects were significant and explained $20.32 \%$ and $24.70 \%$ of the total effect of future time perspective, respectively. The authors presented the reverse model of relations, with mobile phone addiction as a predictor and procrastination as an outcome. What we mean by procrastination the present study is a stable tendency to postpone scheduled tasks and decisions, in accordance with the approach widely adopted in the literature, where procrastination is defined as a personality trait (Schouwenburg \& Lay, 1995).

The main aim of the current study was to investigate the mediating role of future anxiety in the relationship between procrastination (general and decisional) and problematic new media use (i.e., Facebook intrusion and problematic mobile phone use). Based on previous studies, we built a theoretical mediation model (Fig. 1) in which future time perspective-more precisely, one of its aspects: future anxiety-was a mediator between procrastination and Facebook intrusion and between procrastination and problematic mobile phone use. Two dimensions of procrastination were considered: general and decisional procrastination, as they are conceptually different and show different patterns of relations (Di Fabio, 2006; Hen et al., 2021). We hypothesized that both types of procrastination (general and decisional) would be positively associated with problematic new media use (Facebook intrusion and problematic mobile phone use) (H1) and that future anxiety would be positively related to problematic new media use $(\mathrm{H} 2)$. We also expected that future anxiety would mediate the relationship between procrastination (general and decisional) and problematic new media use (H3).

\section{Method}

\section{Participants}

The participants were students living in Poland $(N=478)$, aged 18 to $27(M=19.93, S D=1.77)$. Women constituted $64 \%$ of the sample. The subjects agreed to participate in the study on a voluntary basis and were given no financial remuneration. They were approached in their classrooms and asked to complete the questionnaires. The study was approved by the Research Ethics Board at the authors' institution. 
Fig. 1 The theoretical mediation model of relations between procrastination (general and decisional), future anxiety, and problematic new media use

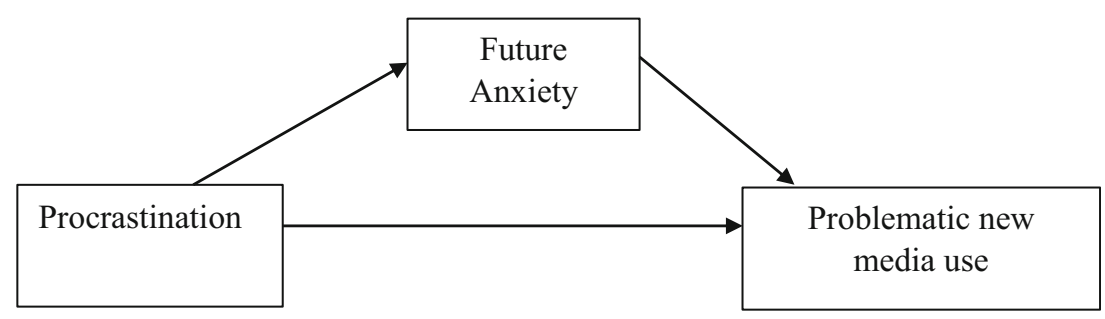

\section{Measures}

The General Procrastination Scale (Lay, 1988) is used to measure procrastination and consists of 20 items rated on a Likert scale from $1=$ strongly disagree to $5=$ strongly agree. Higher total scores indicate a higher level of procrastination. We used the Polish adaptation of the scale (Przepiorka et al., 2016). In present study, Cronbach's alpha coefficient for general procrastination was .77 . The scale measures global tendency to procrastinate across a variety of daily tasks. An example item is: "When it is time to get up in the morning, I most often get right out of bed."

The Decisional Procrastination Scale (Mann, 1982) is a self-report scale measuring delay in making decisions; it consists of five items (e.g., "I don't make a decision unless I really have to"). We used the Polish adaptation of the scale (Przepiorka et al., 2016). The participants were instructed to respond to the assertions provided using a 5 -point scale ( $1=$ strongly disagree, $5=$ strongly agree). Cronbach's alpha reliability of the scale used in our study was $\alpha=.85$.

The Facebook Intrusion Questionnaire by Elphinston and Noller (2011) was developed on the basis of behavioral addiction criteria and a scale measuring phone involvement. It consists of eight items (e.g., "I have been unable to reduce my Facebook use") measuring the association of Facebook involvement tendency with eight aspects of behavioral addiction, namely: cognitive salience, behavioral salience, interpersonal conflict, conflict with other activities, euphoria, loss of control, withdrawal, and relapse and reinstatement. The items are rated on a 7-point Likert scale from $1=$ strongly disagree to $7=$ strongly agree. Cronbach's alpha reliability of the Polish version of the scale was .86 .

Problematic mobile phone use was measured with the Adapted Mobile Phone Use Habits by Smetaniuk (2014), an instrument consisting of 10 items with a bivariate response scale (yes or no). An example item is: "Do you use your mobile phone to escape problems or lift your mood?" Cronbach's alpha reliability of the Polish version of the scale was $\alpha=.84$.

The Future Anxiety Scale-Short Form was developed by Zaleski et al. (2017). This 10-item instrument measures the tendency to think about the future with anxiety and uncertainty and to anticipate disasters in the future (e.g., "I am afraid that the problems which trouble me now will continue for a long time"). Cronbach's alpha reliability of the scale in the present study was $\alpha=.93$.

\section{Results}

In the first step of the analyses, we computed Pearson's correlations among the variables: Table 1 presents the means, standard deviations, and correlations among them. Facebook intrusion and mobile phone use were positively related to general procrastination, decisional procrastination, and future anxiety. Additionally, both types of procrastination were positively related to future anxiety.

In the next step of our analyses, in order to analyze the mediation effects of procrastination (general and decisional) on problematic mobile phone use and Facebook intrusion mediated by future anxiety, we used Zhao's et al. (2010) approach with the Monte Carlo method (5000 samples) to estimate standardized indirect effects with $95 \%$ confidence interval (Mehmetoglu, 2018). The mediation analyses are presented separately for general procrastination and decisional procrastination. However, as there was an interrelation between Facebook intrusion and problematic mobile phone use (Kuss \& Griffiths, 2017), the mediation model included this relationship (see Figs. 2 and 3). We interpreted the mediation effect in accordance with Zhao's et al. (2010, p. 200) guidelines: (1) complementary mediation: an indirect effect and a direct effect both exist and point in the same direction; (2) competitive mediation: an indirect effect and a direct effect both exist and point in opposite directions; (3) indirect-only mediation: an indirect effect exists, but no direct effect (full mediation); (4) direct-only non-mediation: a direct effect exists, but no indirect effect; (5) no-effect non-mediation: neither a direct effect nor an indirect effect exists. Additionally, we computed the ratio of the indirect effect to the total effect (RIT) and the ratio of the indirect effect to the direct effect (RID). RIT indicates what percentage of the effect of the independent variable (procrastination: general and decisional) on the dependent variable (Facebook intrusion and problematic mobile phone use) is mediated by the mediator (future anxiety). RID indicates how many times larger the mediated effect is than the direct effect.

Based on the mediation analysis framework (Mehmetoglu, 2018; Zhao et al., 2010), we found significant mediation effects of future anxiety. Both general procrastination and decisional procrastination exerted a significant indirect effect on problematic new media use (problematic mobile phone use and Facebook intrusion) via future anxiety. More specifically, 
Table 1 Means, Standard Deviations, and Correlations Among the Variables $(N=478)$

\begin{tabular}{llllll}
\hline & $M(S D)$ & 1 & 2 & 3 & 4 \\
\hline 1. Facebook intrusion & $2.73(1.22)$ & - & & \\
2. Problematic mobile phone use & $2.35(0.71)$ & $.63^{* * *}$ & - & & \\
3. Procrastination: general & $2.82(0.53)$ & $.22^{* * *}$ & $.27^{* * *}$ & - & \\
4. Procrastination: decisional & $2.86(0.97)$ & $.31^{* * *}$ & $.42^{* * *}$ & $.58^{* * *}$ & - \\
5. Future anxiety & $3.82(1.57)$ & $.27^{* * *}$ & $.34 * * *$ & $.15^{* *}$ & $.46^{* * *}$ \\
\hline
\end{tabular}

$* p<.05 . * * p<.01 . * * * p<.001$

there was complementary mediation (partial mediation) between decisional procrastination and problematic mobile phone use as well as Facebook intrusion via future anxiety. Additionally, there was a significant indirect effect between general procrastination and problematic new media use (Facebook intrusion and problematic mobile phone use), with future anxiety as a mediator. Considering the statistically significant direct effects between general procrastination and problematic new media use, our results may indicate complementary mediation (partial mediation; see Zhao et al., 2010). Detailed results are shown in Table 2, Fig. 2, and Fig. 3.

\section{Discussion}

In the present study we investigated the relationship between procrastination and problematic new media use and the role of future anxiety as a potential mediator of the effects of general and decisional procrastination on problematic new media use. We found that the students who procrastinated often reported a high tendency to engage in problematic new media use and a high level of future anxiety.
As predicted in H1, individuals with higher levels of both types of procrastination (general and decisional) reported higher levels of Facebook intrusion and problematic mobile phone use. These results are consistent with a previous study, where people who had a tendency to postpone obligations and scheduled tasks were more likely to engage in problematic Internet use or Facebook use (Przepiorka et al., 2016). Another recent study, by Reinecke, Meier, Beutel, et al. (2018b), showed that adolescents high in trait procrastination used the Internet simultaneously for tasks other than work (e.g., during homework) and engaged in problematic Internet use. Other studies also indicate that people procrastinate their duties as a result of excessive engrossment in the social media, engaging in entertainment: games, social media activities, and listening to music (Meier et al., 2016).

Our results showed that future anxiety was positively related to Facebook intrusion and problematic mobile phone use, thus supporting hypothesis H2. Like other studies (Chittaro \& Vianello, 2013; Przepiorka \& Blachnio, 2016), they point to time perspective as a significant predictor of addictive behaviors. Negative attitude towards the past and towards the present is related to avoidant coping strategies (cf. Zimbardo \& Boyd, 1999), which may also increase the tendency to escape

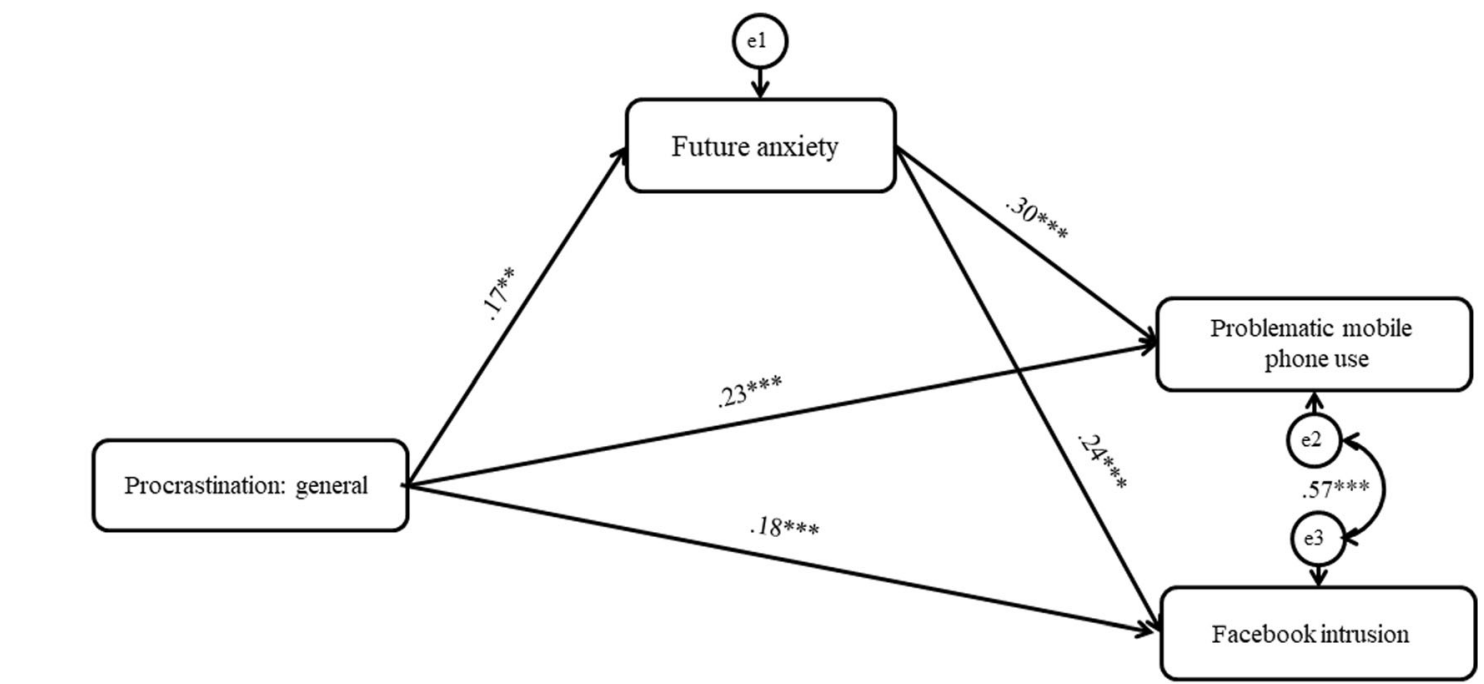

$* * * \mathrm{p}<0.001 ; * * \mathrm{p}<0.01 ; * \mathrm{p}<0.05$

Fig. 2 Mediation model of relations between general procrastination, future anxiety, and problematic new media use 


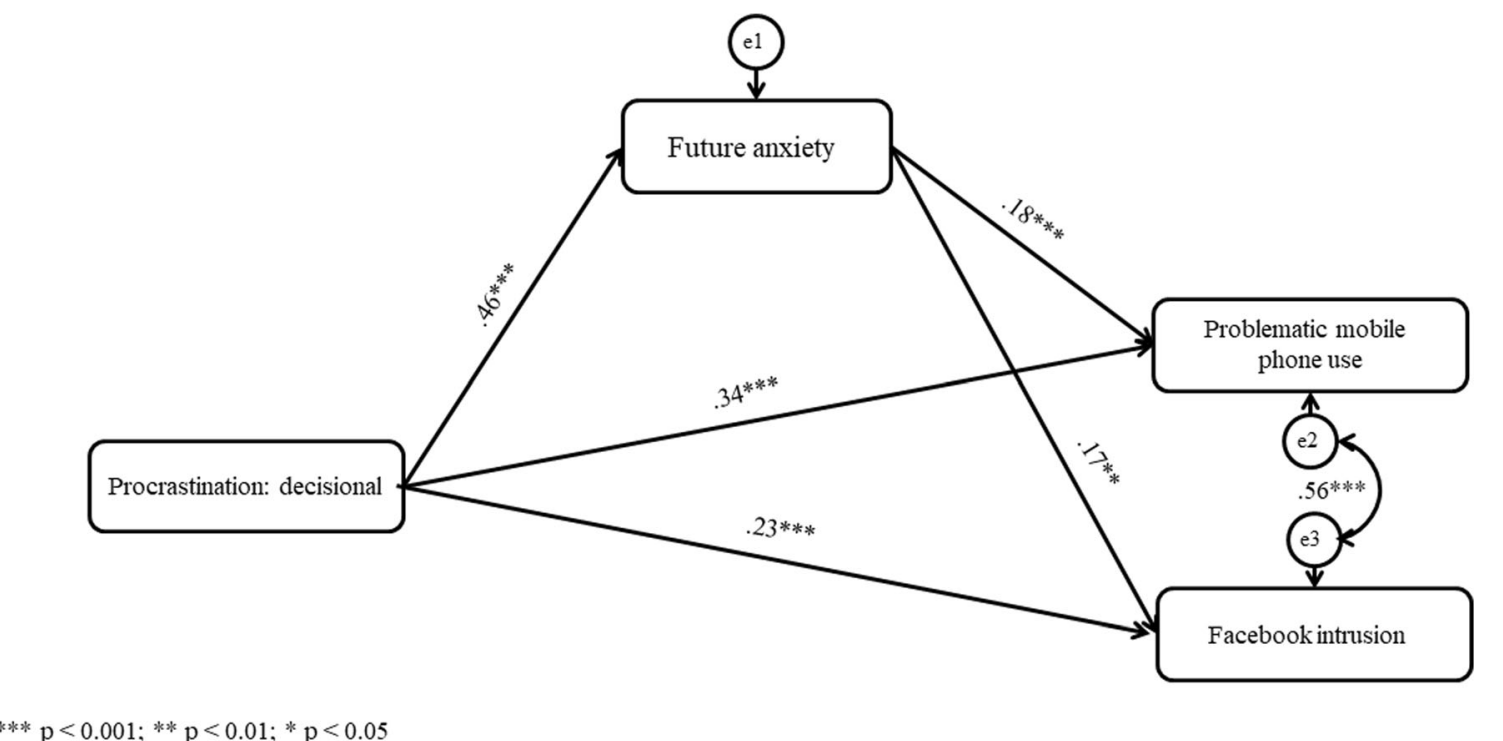

Fig. 3 Mediation model of relations between decisional procrastination, future anxiety, and problematic new media use

into the online world in problem situations (McNicol \& Thorsteinsson, 2017). The results of the present study can be explained in the light of the theory concerning media use and the gratification derived from it (the uses and gratifications theory; Ruggiero, 2000), which postulates the recipient's active role and selection of mass media for the gratification of specific needs. The effect of the media depends on the user's subjective intentions (and characteristics). Individuals with a higher level of future anxiety may exhibit stronger tendencies to become addicted in order to find consolation for their anxiety or worry. New media use may relieve negative mood, which in turn may enhance addictive tendencies. There is confirmation for this in the literature, where the cooccurrence of anxiety disorders with substance use disorders is highlighted (for a review, see Soyka, 2015).

Supporting H3, the results indicated that future anxiety played a mediating role between both types of procrastination and problematic new media use (Facebook intrusion and problematic mobile phone use). Procrastination positively contributes to Facebook intrusion and problematic mobile phone use through future anxiety. Speculatively, it is possible to explain these results as stemming from the fact that individuals high in procrastination think about the future negatively and feel anxious about what may happen to them, which is why, as a solution, they escape into Facebook or reach for the mobile phone. Using these new media might relieve their negative feelings about future tasks to be done and future decisions to be made. This line of explanation finds support in the recent studies, where procrastinators scored low on future time perspective (for a review, see Diaz-Morales et al., 2015). Similarly, the mediating role of past negative and present fatalistic TP orientations was found in the relationship between ADHD symptoms and addictive Facebook use (Settanni et al., 2018). The present study significantly broadens the findings of earlier research (Liu et al., 2018) by considering future anxiety, one of the aspects of future time perspective, in explaining online addiction.

\section{Limitations}

A number of limitations have to be highlighted when interpreting our results. The first limitation is the crosssectional nature of our data, which makes it impossible to
Table 2 Standardized Indirect Effects with $95 \%$ Confidence Intervals

\begin{tabular}{|c|c|c|c|c|c|c|c|}
\hline \multirow[t]{2}{*}{ Model pathways } & \multirow{2}{*}{$\begin{array}{l}\text { Point } \\
\text { estimates }\end{array}$} & \multirow[t]{2}{*}{ Standard error } & \multicolumn{2}{|c|}{$95 \% \mathrm{CI}$} & \multirow[t]{2}{*}{$p$} & \multirow[t]{2}{*}{ RIT } & \multirow[t]{2}{*}{ RID } \\
\hline & & & Lower & Upper & & & \\
\hline PG - Further anxiety - PMPU & 0.045 & 0.015 & 0.017 & 0.076 & .002 & 0.165 & 0.198 \\
\hline PG - Further anxiety - FI & 0.036 & 0.013 & 0.013 & 0.063 & .004 & 0.165 & 0.197 \\
\hline PD - Further anxiety - PMPU & 0.082 & 0.022 & 0.040 & 0.125 & .001 & 0.195 & 0.242 \\
\hline PD - Further anxiety - FI & 0.075 & 0.023 & 0.031 & 0.121 & .001 & 0.248 & 0.330 \\
\hline
\end{tabular}

$\mathrm{PG}=$ procrastination: general; $\mathrm{PD}=$ procrastination: decisional; $\mathrm{PMPU}=$ problematic mobile phone use; $\mathrm{FI}=$ Facebook intrusion. 
determine the causality or direction of effects between the variables. The second limitation stems from the use of selfreport measures in the study. While all our hypotheses were systematically derived from theory and recent empirical findings, alternative interpretations of the pattern of results obtained in this study could be equally legitimate. This refers to the relationship between procrastination, future anxiety, and problematic new media use. In this study, problematic new media use was conceptualized as an outcome of procrastination. This interpretation is supported by previous research (e.g., DíazMorales et al., 2008), where procrastination was treated as a stable personality trait. However, the reverse direction of effects, with new media use increasing the risk of procrastination, would also be plausible. Prior procrastination research has discussed this direction of relationship (Liu et al., 2018). Future research should also explore the reciprocal effects between procrastination and new media use on the basis of longitudinal data. An interesting direction for future studies to pursue would be experimental rather than self-report measurement of procrastination.

\section{Conclusion}

The current study advances the understanding of the relationships among procrastination, future anxiety, and problematic new media use (Facebook intrusion and problematic mobile phone use). It has revealed a significant relationship between different types of procrastination (general and decisional) and problematic new media use in the student population. Our findings also confirm the pivotal role of future time perspective for new media use, with emphasis placed on FA acting as a mediator between procrastination and new media use. The novelty of the presented research is its inclusion of the construct of future anxiety, as what turns out to play an important role in the context of problematic new media use is the way one thinks about the future and what attitude one takes towards it. The findings of the study have important implications for research on problematic Facebook use and problematic mobile phone use. They may be useful for psychologists, psychiatrists, and therapists, both in prevention and in developing online addiction therapies. Moreover, they suggest that a significant emphasis in the education of young people should be placed on intentional behaviors, very strongly associated with future time perspective - particularly on specifying the times of goal achievement, which may prevent procrastination.

Data Availability Statement The datasets generated during and/or analysed during the current study are available from the corresponding author on reasonable request.

\section{Declarations}

The study was approved by the Research Ethics Board at the authors' institution.

Informed Consent Informed consent was obtained from all individual participants included in the study.

Conflict of Interest The authors declare that they have no conflict of interest.

Open Access This article is licensed under a Creative Commons Attribution 4.0 International License, which permits use, sharing, adaptation, distribution and reproduction in any medium or format, as long as you give appropriate credit to the original author(s) and the source, provide a link to the Creative Commons licence, and indicate if changes were made. The images or other third party material in this article are included in the article's Creative Commons licence, unless indicated otherwise in a credit line to the material. If material is not included in the article's Creative Commons licence and your intended use is not permitted by statutory regulation or exceeds the permitted use, you will need to obtain permission directly from the copyright holder. To view a copy of this licence, visit http://creativecommons.org/licenses/by/4.0/.

\section{References}

Akbulut, Y., Dönmez, O., \& Dursun, Ö. Ö. (2017). Cyberloafing and social desirability bias among students and employees. Computers in Human Behavior, 72, 87-95.

Błachnio, A., Przepiórka, A. (2016). Personality and positive orientation in internet and facebook addiction. An Empirical Report From Poland. Computers in Human Behavior, 59, 230-236.

Cambridge (2019). New media. In Cambridge online dictionary. Retrieved from https://dictionary.cambridge.org/pl/dictionary/ english/new-media

Cambridge Business English Dictionary (2019). Cambridge University Press Online. https://dictionary.cambridge.org/pl/dictionary/ english/new-media

Carelli, M. G., Wiberg, B., \& Wiberg, M. (2011). Development and construct validation of the Swedish Zimbardo time perspective inventory. European Journal of Psychological Assessment, 27(4), 220-227. https://doi.org/10.1027/1015-5759/a000076.

Cate, R. A., \& John, O. P. (2007). Testing models of the structure and development of future time perspective: Maintaining a focus on opportunities in middle age. Psychology and Aging, 22(1), 186201. https://doi.org/10.1037/0882-7974.22.1.186.

Chittaro, L., \& Vianello, A. (2013). Time perspective as a predictor of problematic internet use: A study of Facebook users. Personality and Individual Differences, 55(8), 989-993. https://doi.org/10. 1016/j.paid.2013.08.007.

Davey, S., \& Davey, A. (2014). Assessment of smartphone addiction in Indian adolescents: A mixed method study by systematic-review and meta-analysis approach. International Journal of Preventive Medicine, 5(12), 1500-1511.

David, P., Kim, J.-H., Brickman, J. S., Ran, W., \& Curtis, C. M. (2015). Mobile phone distraction while studying. New Media \& Society, 17(10), 1661-1679. https://doi.org/10.1177/1461444814531692.

De-Sola Gutiérrez, J., Rodríguez de Fonseca, F., \& Rubio, G. (2016). Cell-phone addiction: A review. Frontiers in Psychiatry, 7, 175. https://doi.org/10.3389/fpsyt.2016.00175.

Di Fabio, A. (2006). Decisional procrastination correlates: Personality traits, self-esteem or perception of cognitive failure? International 
Journal for Educational and Vocational Guidance, 6(2), 109-122. https://doi.org/10.1007/s10775-006-9000-9.

Díaz-Morales, J. F., \& Ferrari, J. R. (2015). More time to procrastinators: The role of time perspective. In Time perspective theory; Review, research and application: Essays in honor of Philip G. Zimbardo (pp. 305-321). Springer international publishing.

Díaz-Morales, J. F., Ferrari, J. R., \& Cohen, J. (2008). Indecision and avoidant procrastination: The role of morningness-eveningness and time perspective in chronic delay lifestyles. The Journal of General Psychology, 135(3), 228-240. https://doi.org/10.3200/GENP.135.3. 228-240.

Eckert, M., Ebert, D. D., Lehr, D., Sieland, B., \& Berking, M. (2016). Overcome procrastination: Enhancing emotion regulation skills reduce procrastination. Learning and Individual Differences, 52, 10 18.

Effert, B., \& Ferrari, J. (1989). Decisional procrastination: Examining personality correlates. Journal of Social Behavior and Personality, 4(1), 151.

Elphinston, R. A., \& Noller, P. (2011). Time to face it! Facebook intrusion and the implications for romantic jealousy and relationship satisfaction. Cyberpsychology, Behavior and Social Networking, 14(11), 631-635. https://doi.org/10.1089/cyber.2010.0318.

Farran, B. (2004). Predictors of academic procrastination in college students. ProQuest Information \& Learning: US.

Fernie, B. A., Bharucha, Z., Nikčević, A. V., \& Spada, M. M. (2017). The unintentional procrastination scale. Journal of Rational-Emotive \& Cognitive-Behavior Therapy, 35(2), 136-149.

Ferrari, J. (2000). Procrastination and attention: Factor analysis of attention deficit, boredomness, intelligence, self-esteem, and task delay frequencies. Journal of Social Behavior and Personality, 15, 185-196.

Ferrari, J. R., \& Díaz-Morales, J. F. (2007). Procrastination: Different time orientations reflect different motives. Journal of Research in Personality, 41(3), 707-714. https://doi.org/10.1016/j.jrp.2006.06.006.

Ferrari, J. R., \& Roster, C. A. (2018). Delaying disposing: Examining the relationship between procrastination and clutter across generations. Current Psychology, 37(2), 426-431.

Geng, J., Han, L., Gao, F., Jou, M., \& Huang, C.-C. (2018). Internet addiction and procrastination among Chinese young adults: A moderated mediation model. Computers in Human Behavior, 84, 320 333. https://doi.org/10.1016/j.chb.2018.03.013.

Giles, D. (2010). Psychology of the media. Lawrence Erlbaum Associates.

Glick, D. M., Millstein, D. J., \& Orsillo, S. M. (2014). A preliminary investigation of the role of psychological inflexibility in academic procrastination. Journal of Contextual Behavioral Science, 3(2), 8188. https://doi.org/10.1016/j.jcbs.2014.04.002.

Goroshit, M., \& Hen, M. (2018). Decisional, general and online procrastination: Understanding the moderating role of negative affect in the case of computer professionals. Journal of Prevention \& Intervention in the Community, 46(3), 279-294.

Gropel, P., \& Steel, P. (2008). A Mega-Trial Investigation of Goal Setting, Interest Enhancement, and Energy on Procrastination. Personality and Individual Differences, 45, 406-411. https://doi. org/10.1016/j.paid.2008.05.015

Grund, A., \& Fries, S. (2018). Understanding procrastination: A motivational approach. Personality and Individual Differences, 121, 120130 .

Gupta, R., Hershey, D. A., \& Gaur, J. (2012). Time perspective and procrastination in the workplace: An empirical investigation. Current Psychology, 31(2), 195-211. https://doi.org/10.1007/ s12144-012-9136-3.

Harriott, J., \& Ferrari, J. R. (1996). Prevalence of procrastination among samples of adults. Psychological Reports, 78(2), 611-616.https:// doi.org/10.2466/pr0.1996.78.2.611
Hen, M., \& Goroshit, M. (2020). The effects of decisional and academic procrastination on students' feelings toward academic procrastination. Current Psychology, 39(2), 556-563.

Hen, M., Goroshit, M., \& Viengarten, S. (2021). How decisional and general procrastination relate to procrastination at work: An investigation of office and non-office workers. Personality and Individual Differences, 172, 110581.

Holman, E. A., \& Silver, R. C. (1998). Getting "stuck" in the past: Temporal orientation and coping with trauma. Journal of Personality and Social Psychology, 74(5), 1146-1163. https://doi. org/10.1037//0022-3514.74.5.1146.

Jackson, T., Fritch, A., Nagasaka, T., \& Pope, L. (2003). Procrastination and perceptions of past, present, and future. Individual Differences Research, 1(1), 17-28.

Jones, J. M., Banicky, L., Lasane, T., \& Pomare, M. (1996). The temporal orientation scale. Unpublished measure available from T. Lasane, Department of Psychology, St. Mary's college, St. Mary's City, MD.

Kamran, W., \& Fatima, I. (2013). Emotional intelligence, anxiety and procrastination in intermediate science students. Pakistan Journal of Social and Clinical Psychology, 11(2), 3-6.

Karatas, H. (2015). Correlation among academic procrastination, personality traits, and academic achievement. Anthropologist, 20(1), 2.

Kim, K. R., \& Seo, E. H. (2015). The relationship between procrastination and academic performance: A meta-analysis. Personality and Individual Differences, 82, 26-33.

Kim, J., Hong, H., Lee, J., \& Hyun, M. H. (2017). Effects of time perspective and self-control on procrastination and internet addiction. Journal of Behavioral Addictions, 6(2), 229-236. https://doi.org/10. 1556/2006.6.2017.017.

Kooij, D. T. A. M., de Lange, A. H., Jansen, P. G. W., \& Dikkers, J. S. E. (2013). Beyond chronological age. Examining perceived future time and subjective health as age-related mediators in relation to workrelated motivations and well-being. Work \& Stress, 27(1), 88-105. https://doi.org/10.1080/02678373.2013.769328.

Kuhl, J. (1984). Volitional Aspects of Achievement Motivation and Learned Helplessness: Toward a Comprehensive Theory of Action Control. In B. A. Maher (Ed.), Progress in Experimental Personality Research, 13; 99-171. New York: Academic Press.

Kuss, D. J., \& Griffiths, M. D. (2017). Social networking sites and addiction: Ten lessons learned. International Journal of Environmental Research and Public Health, 14(3), 311. https:// doi.org/10.3390/ijerph14030311.

Lay, C. H. (1986). At last, my research article on procrastination. Journal of Research in Personality, 20(4), 474-495. https://doi.org/10.1016/ 0092-6566(86)90127-3.

Lepp, A., Barkley, J. E., \& Karpinski, A. C. (2014). The relationship between cell phone use, academic performance, anxiety, and Satisfaction with Life in college students. Computers in Human Behavior, 31, 343-350. https://doi.org/10.1016/j.chb.2013.10.049.

Lepp, A., Li, J., \& Barkley, J. E. (2016). College students' cell phone use and attachment to parents and peers. Computers in Human Behavior, 64, 401-408. https://doi.org/10.1016/j.chb.2016.07.021.

Liu, L. Q., Min, G., Yue, S. T., \& Cheng, L. S. (2018). The influence of mobile phone addiction on procrastination: A moderated mediating model. Journal of Ergonomics, 8(3), 1-6. https://doi.org/10.4172/ 2165-7556.1000232.

Logan, R. (2010). Understanding new media: Extending Marshall McLuhan. Peter Lang Publishing.

Lukavska, K. (2012). Time perspective as a predictor of massive multiplayer online role-playing game playing. Cyberpsychology, Behavior and Social Networking, 15(1), 50-54. https://doi.org/10. 1089/cyber.2011.0171.

Mann, L. (1982). Decision-making questionnaire. Unpublished scale. Flinders University of South Australia. 
McNicol, M. L., \& Thorsteinsson, E. B. (2017). Internet addiction, psychological distress, and coping responses among adolescents and adults. Cyberpsychology, Behavior and Social Networking, 20(5), 296-304. https://doi.org/10.1089/cyber.2016.0669.

Mehmetoglu, M. (2018). Medsem: A Stata package for statistical mediation analysis. International Journal of Computational Economics and Econometrics, 8(1), 63-78. https://doi.org/10.1504/IJCEE.2018. 088321.

Meier, A., Reinecke, L., \& Meltzer, C. E. (2016). "Facebocrastination"? Predictors of using Facebook for procrastination and its effects on students' well-being. Computers in Human Behavior, 64, 65-76.

Milgram, N., \& Tenne, R. (2000). Personality correlates of decisional task avoidant procrastination. European Journal of Personality, 14(2), 141-156. https://doi.org/10.1002/(SICI)1099-0984(200003/04)14: 2<141::AID-PER369>3.0.CO;2-V

Nguyen, B., Steel, P., \& Ferrari, J. (2013). Procrastination's impact in the workplace and the workplace's impact on procrastination. International Journal of Selection and Assessment, 21(4), 388-399.

Nuttin, J. R. (1964). The future time perspective in human motivation and learning. Acta Psychologica, 23(C), 60-82.

Odaci, H. (2011). Academic self-efficacy and academic procrastination as predictors of problematic internet use in university students. Computers \& Education, 57(1), 1109-1113. https://doi.org/10. 1016/j.compedu.2011.01.005.

Przepiorka, A., \& Blachnio, A. (2016). Time perspective in internet and Facebook addiction. Computers in Human Behavior, 60, 13-18. https://doi.org/10.1016/j.chb.2016.02.045.

Przepiorka, A., Błachnio, A., \& Díaz-Morales, J. F. (2016). Problematic Facebook use and procrastination. Computers in Human Behavior, 65, 59-64. https://doi.org/10.1016/j.chb.2016.08.022.

Przepiorka, A., Blachnio, A., \& Cudo, A. (2019). The role of depression, personality, and future time perspective in internet addiction in adolescents and emerging adults. Psychiatry Research, 272, 340-348. https://doi.org/10.1016/j.psychres.2018.12.086.

Qaisar, S., Akhter, N., Masood, A., \& Rashid, S. (2017). Problematic mobile phone use, academic procrastination and academic performance of college students. The Journal of Educational Research, 20(2), 201.

Rahardjo, W., Juneman, A., \& Setiani, Y. (2013). Computer anxiety, academic stress, and academic procrastination on college students. Journal of Education and Learning, 7(3), 147-152. https://doi.org/ 10.11591/edulearn.v7i3.179.

Rebetez, M. M. L., Barsics, C., Rochat, L., D’Argembeau, A., \& Van der Linden, M. (2016). Procrastination, consideration of future consequences, and episodic future thinking. Consciousness and Cognition, 42, 286-292. https://doi.org/10.1016/j.concog.2016.04.003.

Reinecke, L., Meier, A., Aufenanger, S., Beutel, M. E., Dreier, M., Quiring, O., Stark, B., Wölfling, K., \& Müller, K. W. (2018a). Permanently online and permanently procrastinating? The mediating role of internet use for the effects of trait procrastination on psychological health and well-being. New Media \& Society, 20(3), 862-880. https://doi.org/10.1177/1461444816675437.

Reinecke, L., Meier, A., Beutel, M. E., Schemer, C., Stark, B., Wölfling, K., \& Müller, K. W. (2018b). The relationship between trait procrastination, internet use, and psychological functioning: Results from a community sample of German adolescents. Frontiers in Psychology, 9, 913. https://doi.org/10.3389/fpsyg.2018.00913.

Ruggiero, T. E. (2000). Uses and gratifications theory in the 21st century. Mass Communication and Society, 3(1), 3-37. https://doi.org/10. 1207/S15327825MCS0301 02.

Saiphoo, A. N., Halevi, L. D., \& Vahedi, Z. (2020). Social networking site use and self-esteem: A meta-analytic review. Personality and Individual Differences, 153, 109639.

Schouwenburg, H. C., \& Lay, C. H. (1995). Trait procrastination and the big-five factors of personality. Personality and Individual
Differences, 18(4), 481-490. https://doi.org/10.1016/01918869(94)00176-S.

Settanni, M., Marengo, D., Fabris, M. A., \& Longobardi, C. (2018). The interplay between ADHD symptoms and time perspective in addictive social media use: A study on adolescent Facebook users. Children and Youth Services Review, 89, 165-170. https://doi.org/ 10.1016/j.childyouth.2018.04.031.

Sirois, F. M. (2014a). Out of sight, out of time? A meta-analytic investigation of procrastination and time perspective. European Journal of Personality, 28(5), 511-520. https://doi.org/10.1002/per.1947.

Sirois, F. M. (2014b). Procrastination and stress: Exploring the role of self-compassion. Self and Identity, 13(2), 128-145.

Sirois, F. M., \& Pychyl, T. (2013). Procrastination and the priority of short-term mood regulation: Consequences for future self. Social and Personality Psychology Compass, 7(2), 115-127. https://doi. org/10.1111/spc3.12011.

Sirois, F. M., Melia-Gordon, M. L., \& Pychyl, T. A. (2003). "I'll look after my health, later": An investigation of procrastination and health. Personality and Individual Differences, 35(5), 1167-1184. https://doi.org/10.1016/S0191-8869(02)00326-4.

Smetaniuk, P. (2014). A preliminary investigation into the prevalence and prediction of problematic cell phone use. Journal of Behavioral Addictions, 3(1), 41-53. https://doi.org/10.1556/JBA.3.2014.004.

Soyka, M. (2015). Comorbidity of anxiety disorders and substance use. In G. Dom \& F. Moggi (Eds.), Co-occurring addictive and psychiatric disorders: A practice-based handbook from a European perspective (pp. 149-160). Springer.

Specter, M. H., \& Ferrari, J. R. (2000). Time orientations of procrastinators: Focusing on the past, present, or future? Journal of Social Behavior \& Personality, 15(5), 197-202.

Stead, R., Shanahan, M. J., \& Neufeld, R. W. J. (2010). "I'll go to therapy, eventually": Procrastination, stress and mental health. Personality and Individual Differences, 49(3), 175-180. https:// doi.org/10.1016/j.paid.2010.03.028.

Steel, P. (2007). The nature of procrastination: A meta-analytic and theoretical review of quintessential self-regulatory failure. Psychological Bulletin, 133(1), 65-94. https://doi.org/10.1037/ 0033-2909.133.1.65.

Steel, P. (2010). Arousal, avoidant and decisional procrastinators: Do they exist? Personality and Individual Differences, 48(8), 926934. https://doi.org/10.1016/j.paid.2010.02.025.

Tibbett, T. P., \& Ferrari, J. R. (2015). The portrait of the procrastinator: Risk factors and results of an indecisive personality. Personality and Individual Differences, 82, 175-184. https://doi.org/10.1016/j.paid. 2015.03.014.

van Beek, W., Berghuis, H., Kerkhof, A., \& Beekman, A. (2011). Time perspective, personality and psychopathology: Zimbardo's time perspective inventory in psychiatry. Time \& Society, 20(3), 364-374. https://doi.org/10.1177/0961463X10373960.

Zaleski, Z. (1991). Psychologia zachowań celowych [the psychology of intentional behaviors]: Państwowe Wydawnictwo Naukowe.

Zaleski, Z. (1996). Future anxiety: Concept, measurement, and preliminary research. Personality and Individual Differences, 21(2), 165174. https://doi.org/10.1016/0191-8869(96)00070-0.

Zhao, X., Lynch Jr., J. G., \& Chen, Q. (2010). Reconsidering baron and Kenny: Myths and truths about mediation analysis. Journal of Consumer Research, 37(2), 197-206.

Zimbardo, P. G., \& Boyd, J. N. (1999). Putting time in perspective: A valid, reliable individual-differences metric. Journal of Personality and Social Psychology, 77(6), 1271-1288. https://doi.org/10.1037/ 0022-3514.77.6.1271.

Publisher's Note Springer Nature remains neutral with regard to jurisdictional claims in published maps and institutional affiliations. 